\title{
Personal values and cancer treatment refusal
}

Marli Huijer and Evert van Leeuwen Vrije Universiteit, Amsterdam, the Netherlands

\begin{abstract}
This pilot study explores the reasons patients have for refusing chemotherapy, and the ways oncologists respond to them. Our hypothesis, generated from interviews with patients and oncologists, is that an ethical approach that views a refusal as an autonomous choice, in which patients are informed about the pros and cons of treatment and have to decide by weighing them, is not sufficient. A different ethical approach is needed to deal with the various evaluations that play a role in treatment refusal. If patients forgo further treatment, while curative or palliative methods are available, there is no perspective from which to integrate the weighing of pros and cons of treatment and the preferences and values of individual cancer patients. A discrepancy thus results as regards what "good reasons" are, evoking misunderstandings or even breaking off communication. Suggestions are given for follow up research.

(Fournal of Medical Ethics 2000;26:358-362)

Keywords: Ethics; oncology; treatment refusal
\end{abstract}

\section{Introduction}

One of the principles of modern cancer care is that it should be responsive to the patients' wishes and consistent with their values. ${ }^{1}$ This is why it is important to understand how patients arrive at treatment decisions. As yet, most studies focus on the decision making processes related to the choice between cancer-directed therapies and palliative care.$^{2-4}$ Little attention is devoted to understanding why and when cancer patients decide to refuse treatment.

Refusing chemotherapy is not a common reaction on the part of cancer patients. The majority readily accept primary treatment recommendations. ${ }^{5}$ If the choice were totally theirs, most cancer patients would be likely to opt for chemotherapy, even if there were only a small chance of improvement. ${ }^{6}$ What leads some patients to go in the opposite direction? A search of Medline on treatment refusal and oncology yielded some studies giving information on variables that influence the decision, such as nausea, ${ }^{7}$ high levels of education, being a "natural" risk taker, ${ }^{6}$ fear of the side effects of chemotherapy and of the disease, ${ }^{8}$ and quality of life after cancer treatment. ${ }^{9}$ No information was available on the moral issues involved.
This pilot study explores the moral reasons patients have for refusing chemotherapy, the ways oncologists respond, and how physicians and patients communicate about them. Our data, although limited, suggest that treatment refusals are not only based on weighing the pros and cons of treatment, but also on the patient's personal circumstances, beliefs, preferences, values and feelings. Further research is needed into these other factors and also into how personal values and judgments are communicated in a medical context.

\section{Method}

The main purpose of the pilot study was to develop some understanding of the ethical aspects involved in treatment refusal, and to generate research questions for further research. Cancer patients who refused treatment and their oncologists were interviewed in a semi-structured way, making it possible to get an initial impression of the problems at hand. The pilot study was performed in the department of medical oncology at the Academic Hospital of the Vrije Universiteit (AZVU), Amsterdam. Cancer patients from all over the Netherlands come to this highly sophisticated department, which provides the latest treatment options.

After the ethics committee of the AZVU had given its approval, in June 1996 the eight oncologists in the department were asked to report how many of their still living patients refused treatment in 1995. It appeared that 12 patients had refused. Of them, nine were too ill to participate or were dying, and three were able to talk and agreed to participate. All patients were female, age 49, 56 and 73 , diagnosed with breast cancer, metastasised breast cancer and metastasised ovarian cancer. All had previous experience with chemotherapy. The time range between the consultation on the treatment refusal and the interview varied from several months to a year. Although the number of patients was low, we decided to continue the study. Of the eight oncologists in the department, three were selected by drawing lots. These three oncologists were male, age between 46 and 55, their level of experience about 10-15 years. The interview concerned the last patient with whom they had a conversation on treatment refusal. Grounded theory methods were used to analyse the interviews. ${ }^{10-12}$ The steps included: a) examining the reasons for treatment refusal, evaluation of the refusal and evaluation of communication about the refusal; b) studying the interviews with the patients 
and oncologists for themes; c) developing categories to describe common themes in the interviews; d) refining the categories by relating them to literature on treatment refusal. In this process, the following categories were developed:

weighing the pros and cons of chemotherapy; the patient's context; good reasons, and

communication on treatment refusals.

WEIGHING THE PROS AND CONS OF CHEMOTHERAPY The category of weighing pros and cons is compatible with the bioethical perspective on informed refusal in which competence, voluntariness, disclosure of information, recommendation of a plan, understanding, decision against a plan, and authorisation of the chosen plan are required..$^{13}$ Based on the understanding of information, competent and reasonable patients can be expected to refuse treatment because there are more cons than pros.

Patients

All patients in the pilot study cited as one set of reasons that the advantages of treatment did not outweigh the disadvantages. As one of them said "My motivation to forgo chemotherapy is that too many goods things break down in proportion to the bad ones". The disadvantages of chemotherapy that she and the other patients referred to were: negative experiences with previous courses, expected side effects, perceived effects on others, uncertainty of the resulting effect on their health, and the idea that an adjuvant treatment makes no sense as long as they feel well. Side effects and medical uncertainties regarding the effects of chemotherapy can be viewed as rational or reasonable grounds for patients to refuse the treatment

\section{Oncologists}

The oncologists were concerned about the side effects and complications due to chemotherapy. Two of them explicitly mentioned the medical uncertainty about the course of the disease, the actual prognosis, and the results of chemotherapy in the individual patient. Their attitude corresponds to the medical literature, where the narrow therapeutic index and the toxic side effects of chemotherapy are well documented. ${ }^{14}$ An example of weighing the pros and cons, as related by one oncologist, is the case of a 70-year-old woman with breast cancer, who refused chemotherapy after she was diagnosed as having a bone metastasis. She had seen how friends of hers had suffered from chemotherapy. Balancing the pros and cons of chemotherapy, and the disadvantages of urging a patient who does not accept treatment, the oncologist thought the woman had good reasons for her decision.

\section{THE PATIENT'S CONTEXT}

From the interviews it became evident that deciding for or against chemotherapy is not just a matter of weighing the pros and cons. To understand treatment refusal, it was necessary to get a grasp of the contextual aspects related to the decision. "Context" is a rather broad term. Here it denotes all the personal circumstances relevant to someone's decision. In daily life, decisions are influenced by various forms of knowledge, values, belief systems, or meanings of life. ${ }^{15}$ The individual can be seen as a specific intersection of various webs of meaning embedded in his or her particular context. New data, such as the news about having cancer, are interpreted within the contextual framework of these webs. Each patient tries to understand the news within his own language and perspective on life. ${ }^{16}$

\section{Patients}

In the pilot study, patients mentioned such personal circumstances as a financial need to work, a need to study or the care of a dog as important factors in decision making. On a broader scale, it became clear that contextual circumstances were also relevant to the attitude to life, suffering and death. Ten Kroode has argued that the common attitude to suffering and death in the Netherlands is one of disinterest or denial, expressed as: "It won't happen to me", and in the event of misfortune: "Why me?". ${ }^{17}$ This attitude was evident in two patients. Both had planned to reach a ripe old age and were not prepared to die soon. One of them said she wanted to survive, but not if the fight against death meant too much suffering and degenerating: "Why should I lead a dog's life due to terrible therapies if maybe it is awfully nice over there?". Her ambivalence about suffering and dying marked the context in which she refused chemotherapy and hormonal treatment, but was prepared to alter her decision as soon as her condition deteriorated. "In that case, I think something should be done. Otherwise I am heading for death".) A more resigned attitude was expressed by the third patient who was not scared of dying, although she did not know what would come after death. She was content with how she had lived her life, and was grateful for what life had given her. In a way, she was looking forward to joining her dead parents and other beloved ones.

\section{Oncologists}

It is striking that none of the oncologists talked about the context or the personal values of the patients. The refusals were evaluated from a medical (alternative medicine included) or rather narrow psychological perspective (personality of the patient, anxieties, coping style). Hardly anything was said about the patients' values, for instance with regard to their way of living, suffering or dying. This result is in accordance with a more quantitative study on doctor-patient interactions in oncology: in general the exchange of biomedical information dominates the consultation, little "space" is given to psychosocial questions, and issues of lifestyle and wellbeing are rarely discussed. ${ }^{18}$ 
GOOD REASONS FOR TREATMENT REFUSAL

The category of "good reasons" emerged from the interviews with the oncologists. They stated that patients needed "good reasons" to refuse. Otherwise they would certainly try to talk them into accepting treatment. The literature confirms this approach: rationality is often defined as "the ability to make decisions based on good reasons".$^{19}$ It is not clear what "good reasons" are: intelligible in the context of the patient? Intelligible in the medical context? Founded on common sense?

\section{Patients}

From the patients' perspective, "good reasons" are a complex issue as regards the process they have been through. The final decision required extensive deliberation, during which all the aspects of the pros and cons of chemotherapy, the personal circumstances, the attitudes with regard to living, suffering, and dying and the opinions of friends and relatives were weighed. In this deliberation, feelings played an important role: in all the cases, the feeling that it was the right thing to do was decisive. This does not necessarily mean the decision is irrational or irresponsible, but it underscores the fact that standards of rational deliberation are co-dependent on moral factors in the context.

\section{Oncologists}

From the oncologists' perspective, "good reasons" result from a rational balancing of the pros and cons of a treatment. As one of them stated: "It implies having information on a certain problem, being well-informed about the advantages and disadvantages, and balancing the pros and cons against each other. If the pros are heavier than the cons, you should make that decision."

In their opinion, a patient cannot have "good reasons" to refuse treatment if there is a reasonable chance of recovery. Although the percentage deemed sufficient in order vigorously to recommend treatment is not uniformly set, most oncologists do agree that a $15 \%$ chance of recovery is enough reason to persuade the patient to undergo treatment.$^{20}$ One oncologist confirmed this by stating that refusing chemotherapy in these cases is tantamount to a death wish, and he did not hesitate to persuade people to accept chemotherapy.

The oncologists were more qualified in their judgments if chemotherapy was advised as palliation. In that case, the medical results should be considered in combination with the known effects on the quality of life. Notwithstanding this differentiation, the oncologists' attitude to requiring "good reasons" remained the same. In their view, the decision making process is always a balancing of the treatment's pros and cons, which is why the physician has to provide adequate medical information. Patients who refuse on other than medical grounds tend to evoke disapproval.

In two of the cases presented, the oncologists had some doubts about the patients' reasons. Although the oncologists were convinced the decisions had been made autonomously and voluntarily by com- petent and well-informed patients, they found the refusals irrational. In an effort to explain the "irrationality", the oncologists referred to the patients' personalities, their anxieties, their ways of coping with the disease, and/or their commitment to alternative medicine. The oncologists' doubts about the rationality of the decisions were reinforced by the fact that the patients did not want to give a rational explanation for their refusals, but told the physicians they had the feeling they should not do it.

\section{COMMUNICATING ABOUT REFUSALS}

Communication in oncology is predominantly focused on truth-telling. ${ }^{21}$ Little is known about communication to do with treatment refusals. Although we did not find any empirical studies on how oncologists respond to, and communicate about, treatment refusals, there is some evidence that the patients' decision to refuse further treatment is not easy for them to accept. ${ }^{12}$

\section{Patients}

Only one of the patients felt that her physician respected her decision, although there was no communication about her reasons. The other patients' interviews showed that communication became difficult because the oncologists felt their refusals were based on irrational grounds. The patients did not get a chance to talk about their values and emotions and the reasons for their refusals. The difference of opinion about the final decision made these patients end the communication because their oncologists did not agree. One oncologist suggested that the patient had allowed her children to change her mind. She tried to convince him that she herself was responsible. After it became clear that she was going to be persistent about her refusal, the oncologist did not give her any further information. Another patient said her physician had tried to persuade her to continue therapy by telling her that without it, she would soon be dead. When she asked him for mental support, he would not provide it.

\section{Oncologists}

In the cases related by the oncologists, they all said that although they did not agree with a patient's refusal, they still respected the patient's choice. In these cases, the difference of opinion between the physician and the patient opened a specific discussion about rational decision making. The physicians wanted to dissuade the patients by questioning the rationality of their decision, and the patients wanted to persuade the physicians of their right to refuse. If the patients did not succeed in a rational or reasonable way, they tried to persuade the physicians in other ways (charm, appealing to their feelings). On one occasion a difference of opinion discharged into termination of the communication process, and the patient did not return to the outpatient clinic. 


\section{Results}

The pilot study yielded very few respondents. The main cause for the small sample size must be sought in the retrospective design, which led to too large a time range between refusal and interviews. Most patients were too ill to participate or had already died. A second reason for the low response might be the composition of the patient population of the AZVU. According to the oncologists, most of their patients are prepared to fight cancer and know that the AZVU provides them with the latest treatment options. We did not find statistical evidence for the overall incidence of treatment refusal in oncology. A third reason might be that patients who refuse treatment withdraw themselves from the care of the oncologist.

The limited data of the pilot study showed that in the decision making process, the oncologists were guided chiefly by the weighing of pros and cons of the treatment. The patients were also guided by a mixture of feelings, personal circumstances, goals, beliefs, thoughts and calculations. The various reflections on life, suffering and death expressed by the patients exhibit a close link to the contex relevant to the treatment refusal. In the informed consent procedure, these reflections are usually overruled by the attention devoted to weighing the medical pros and cons of treatment. If a physician felt there were no good reasons for a treatment refusal, a deadlock often occurred. In this situation, the physicians tried to convince the patient that the weighing of pros and cons led to another conclusion, whereas the patients asked for understanding of and respect for the reasons and feelings which inspired the treatment refusal.

The results of the study indicate that further research is important to get a better insight into the role that the patients' view of life, their values and judgments play in the decision making process, and in the ways the communication about these can be put into practice. ${ }^{22}$

\section{Discussion}

Contemporary informed refusal procedures require that physicians respect their patients' decision to forgo possibly life-sustaining chemotherapy if the patients have decision making capacity. ${ }^{23}$ This legally stipulated form of respect does not mean the physician has to agree with the decision. One way of dealing with a difference of opinion is by saying that the refusal is based on irrational grounds, even if the patient is competent. The participating oncologists concluded that the patients were making an irrational choice if, after balancing the pros and cons, they did not opt for the course of action with the most pros. The rationality of a choice was defined by medical values such as the chance of their recovering, of prolonging their life or of relieving their symptoms.

The interviews with the patients showed that what might have seemed foolish in a medical context actually resulted from another balancing process in the patient's personal context. The refusals could be better comprehended in the framework of the patients' broader worldview. Within that context, personal values, emotions, beliefs and attitudes towards life, suffering and death seemed to provide "good reasons" for patients to forgo treatment.

Our hypothesis, generated from the interviews, is that the ethical approach to "informed refusal", with the patient expected to weigh the pros and cons of treatment and to be able to formulate good reasons for a treatment consent or refusal, does not deal adequately with the various evaluations and judgments that play a role in the decision to forgo treatment. In addition, the communication between the patient and the physician fails to integrate the medical balancing of pros and cons with the personal perspective of the patient. This makes it impossible to develop standards by which comparative evaluations can be made.

Based on the conclusions of the pilot study, follow up research will be done in a prospective manner. To include enough patients, the study will be extended to cancer care provided by general practitioners, nursing homes and hospitals. Not only cancer patients who forgo the advised cancer treatment will be included, but also patients who accept the treatment. In this way a comparison of the different moral deliberations becomes possible. The research aims to enhance the making explicit of the inclusion of personal values and judgments in communication within the medical context.

Marli Huijer, $M D, M P h, P h D$, is a Postdoctoral Researcher in the Faculty of Philosophy, Rijks University, Groningen, the Netherlands. Evert van Leeuwen, MPh, PhD, is Professor in Philosophy and Medical Ethics, the Faculty of Medicine, Vrije Universiteit, Amsterdam, the Netherlands.

\section{References}

1 Anonymous (American Society of Clinical Oncology). Cancer care during the last phase of life. Fournal of Clinical Oncology 1998;16:1986-96.

2 Weeks JC, Cook EF, O'Day SJ, Peterson LM, Wenger N, Reding D, et al. Relationship between cancer patients' predictions of prognosis and their treatment preferences. Fournal of the American Medical Association 1998;279:1709-14.

3 Hack TF, Degner LF, Dyck DG. Relationship between preferences for decisional control and illness information among women with breast cancer: a quantitative and qualitative analysis. Social Science and Medicine 1994;39:279-89.

4 Bilodeau BA, Degner LF. Information needs, sources of inforBilodeau BA, Degner LF. Information needs, sources of inforOncology Nursing Forum 1996;23:691-96.

5 Siminoff LA, Fetting JH. Factors affecting treatment decisions

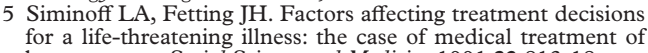
breast cancer. Social Science and Medicine 1991;32:813-18.

6 Slevin ML, Stubbs L, Plant, HJ, Wilson P, Gregory WM Armes PJ, et al. Attitude to chemotherapy: comparing views of patients with cancer with those of doctors, nurses, and general public. British Medical fournal 1990;300:1458-60.

7 Jenns K. Importance of nausea. Cancer Nursing 1994;17:48893.

8 Brock DW, Wartman SA. Sounding board. When competent patients make irrational choices. New England fournal of Medicine 1990;322:1595-9.

9 McKenna RJ. Clinical aspects of cancer in the elderly. Treatment decisions, treatment choices, and follow-up. $C A N$ CER Supplement 1994;74:2107-16.

10 Glaser B, Strauss A. The discovery of grounded theory. Chicago: Aldine, 1967. 
11 Strauss A, Corbin J. Basics of qualitative research. Grounded theory. Newbury Park, London/New Delhi: SAGE Publication 1990 .

12 Strauss A, Corbin J, eds. Grounded theory in practice. London/New Delhi: SAGE Publications, 1997.

13 Beauchamp TL, Childress JF. Principles of biomedical ethics [4t ed]. New York/Oxford: Oxford University Press, 1994:145-6.

14 Smith TJ, Bodurtha JN. Ethical considerations in oncology: balancing the interests of patients, oncologists, and society. fournal of Clinical Oncology 1995;13:2464-70.

15 Rose N. Inventing ourselves. Psychology, power and personhood. Cambridge: Cambridge University Press, 1996.

16 Saillant F. Discourse, knowledge and experience of cancer: a life story. Culture, Medicine and Psychiatry 1990;14:81-94.

17 Ten Kroode H. Het verhaal van kankerpatiënten: Oorzaakstoekenning en betekenisverlening. Een onderzoek naar het verband toekenning en betekenisverlening. Een onderzoek naar het verband

18 Ford S, Fallowfield L, Lewis S. Doctor-patient interactions in oncology. Social Science and Medicine 1996;11:1511-19.
19 Wreen MJ. Autonomy, religious values, and refusal of lifesaving medical treatment. Fournal of Medical Ethics 1991;17:124-30. $20 \mathrm{McGrath}$ P. It's ok to say no! A discussion of ethical issues arising from informed consent to chemotherapy. Cancer Nursing 1995;18:97-103.

21 Surbone A, Zwitter M, eds. Communication with the cancer patient. Information \& truth. New York: The New York Academy of Sciences, 1997

22 See, for an example of a communication skills training in which oncologists shifted to a more patient-centred interviewing: Fallowfield L, Lipkin M, Hall A. Teaching senior oncologists communication skills: results from phase I of a comprehensive longitudinal program in the United Kingdom. Fournal of Clinical Oncology 1998;16:1961-8.

23 Council on Ethical and Juridical Affairs, American Medical Association. Council report. Decisions near the end of life. Association. Council report. Decisions near the end of life. In the Netherlands this obligation is stipulated by the Law on Medical Treatment Agreement (1995). 